\title{
Estimation of Health-State Utility Values and Factors Driving Health-Related Quality of Life in People Living with HIV and AIDS and Receiving CART in Germany: Baseline Analysis of a Cohort Study
}

\author{
Martina Treskova ${ }^{1}$ (D) - Stefan Scholz ${ }^{1} \cdot$ Alexander Kuhlmann $^{1} \cdot$ Jörg Mahlich $^{2,3}$. \\ Matthias Stoll ${ }^{4}$
}

Received: 18 September 2019 / Accepted: 9 March 2021 / Published online: 30 March 2021

(C) The Author(s) 2021

\begin{abstract}
HIV has become a chronic disease since widespread of combined antiretroviral therapy (cART). Understanding the influence of therapeutic and preventive interventions on health-related quality of life (HRQoL) of people living with HIV and AIDS (PLWHA) is important. Information about health state utilities and HRQoL in PLWHA after the introduction of cART is limited, especially in Germany. The study aims to estimate and describe health state utilities and HRQoL in PLWHA in Germany and explore the effects of patient characteristics, clinical and treatment factors. Utilities and HRQoL in PLWHA in Germany were measured with the generic EQ-5D-3L questionnaire. Health state utilities were calculated based on the EQ-5D descriptive system using the German EQ-5D-3L time trade-off (TTO) value set. HRQoL was calculated based on the EQ visual analogue scale (EQ-VAS). Extensive descriptive analyses were performed to represent utility values for different groups of the patients. Generalized linear models (GLMs) with beta-inflated distributions were used to determine patient characteristics and clinical factors that influence TTO utilities and VAS scores. 1056 PLWHA completed the EQ-5D-3L questionnaires at the beginning of the study. The mean TTO utility value is 0.912 ( $\mathrm{SD} \pm 0.154$ ), and the mean VAS HRQoL is 84.32 ( $\mathrm{SD} \pm$ 18.55). "Anxiety/depression" and "pain/physical discomfort" are the most affected dimensions. A longer period of living with HIV, a lower CD4-cell count, having symptomatic HIV or AIDS and an increased number of changes in therapy are associated with decreased utilities and a lower probability of having HRQoL of perfect health. No significant effect of duration of regimen was found. Depression significantly decreases TTO utility values. Higher education, full-time employment and female gender are associated with higher utilities. The resulted EQ-VAS values for PLWHA in Germany are comparable with EQ-VAS estimates for the general population. The
\end{abstract}

Martina Treskova

mt@ cherh.de

Extended author information available on the last page of the article 
obtained estimates can be used as inputs for health economic evaluations of HIVinterventions. Addressing anxiety and depression may reduce the quality of life impairment in PLWHA. Impact of comorbidities needs further investigation.

Keywords HIV · Quality of life · Determinants of HRQoL · EQ VAS · TTO · EQ-5D · Germany $\cdot$ PLWHA

\section{Introduction}

Combined antiretroviral therapy (cART) sustains HIV-virological suppression and consecutively immunological reconstitution in people living with HIV infection(Pichenot et al., 2012; Teeraananchai et al., 2017). If cART is initiated timely and taken regularly, it can prevent HIV transmission, reduce HIV-related morbidity (Cihlar \& Fordyce, 2016) and increase life-expectancy of PLWHA close to that of the general population(Gueler et al., 2017). Nonetheless, HIV infections and HIV-caused morbidity and mortality continue to be a public health issue. In Germany, the Robert Koch-Institute estimated 86,000 $(80,000-92,400)$ people living with HIV with 68,800 receiving cART by the end of 2017 (Robert Koch-Institut, 2018).

Given the current public health burden of chronic HIV infections and ongoing research and development of new therapies(Cihlar \& Fordyce, 2016), prevention strategies(Heneine \& Kashuba, 2012) and screening programs, health economic evaluations are required to provide information for decision-making in HIV-management. Economic evaluations comprise of weighing the costs and benefits of alternative strategies and provide comparative analyses of payoffs of different courses of action (Briggs et al., 2011). Quality-adjusted life-years (QALYs) is a widely applied measure of health outcomes in economic evaluations and recommended by several decision-making bodies in public health (Sanders et al., 2016; NICE, 2014; CADTH, 2017; Pharmaceutical Benefits Advisory Committee, 2016; Zorginstituut Nederland, 2016; STIKO). In order to calculate QALY for a given health condition health utilities (also known as quality of life weights) are necessary. For application in health economic evaluations, indirect elicitation methods, which are based on pre-scored generic preference-based measures, are preferred (Whitehead \& Ali, 2010). EuroQol (EQ)-5D(Kind, 1996), the Short Form 6D (SF6D)(Brazier et al., 2002) and the Health Utilities Index (HUI)(Horsman et al., 2003) constitute commonly used generic questionnaires applied in the measurement of health utility values.

Additionally, due to the chronic nature of HIV infection measurement of health-related quality of life plays a crucial role in our understanding of the impacts of life-long therapeutic interventions on the patients' health. Previous literature shows wide variations of HRQoL across socio-demographic and clinical characteristics of PLWHA. Women with HIV have generally reported lower HRQoL than men (Briongos Figuero et al., 2011; Protopopescu et al., 2007; Rao et al., 2007). Whereas drug use and older age are both generally associated with lower physical health (Fleming et al., 2004; Gibson et al., 2011; Kanwal et al., 2005; Liu, Johnson, et al., 2006a; Ruiz Perez et al., 2005), being in a stable relationship may contribute to a more favourable HRQoL (Préau, Protopopescu, et al., 2007b). In addition, education and employment seem to influence both physical and mental health status (Fleming et al., 2004; Hays et al., 2000; Zinkernagel et al., 2001). 
Several clinical and disease-related factors appear to be related to HRQoL in PLWHA as well. Specifically, a better virological status has been shown to be associated with better overall (Schroecksnadel et al., 2008), physical (Call et al., 2000), and mental health (Fleming et al., 2004). Both HIV symptoms and comorbidities tend to impair HRQoL, particularly with regard to physical health. Lipodystrophy, or the redistribution of fat, that often occurs in PLWHA, is stigmatizing and hence especially aversive for patients (Holzemer et al., 2009; Murri et al., 1997). The same is valid for depression (Fleming et al., 2004) and substance abuse (Korthuis et al., 2008).

Antiretroviral therapy (ART) has conflicting effects on HRQoL because, while ART tends to reduce HIV-related symptoms and improve life expectancy, it can also lead to unintended adverse side effects and worsening of certain symptoms, such as lipodystrophy (Liu, Ostrow, et al., 2006b) and immunoreconstitutional inflammatory syndromes (Stoll \& Schmidt, 2004). However, recently ART has been improved due to the development of new antiretroviral drugs with fewer adverse effects. Furthermore, the development of once-daily, single-tablet combination preparations opened up improved therapeutic opportunities. As a result, studies have shown a positive effect of ART on HRQoL (Airoldi et al., 2010; Esté \& Cihlar, 2010).

Assessment of HRQoL in PLWHA in Germany is scarce. Further, to our knowledge, there are no available estimates of utilities which can be used in health economic evaluations of HIV-mitigation strategies. Two recent studies (Drewes et al., 2020; Sabranski et al., 2020) investigate aspects of HRQoL in German HIV-patient using SF-12 instrument. They showed the overall negative impact of HIV infection on mental and physical health and found impairing effects of age, depression and unemployment (Sabranski et al., 2020) and impact of different comorbidities (Drewes et al., 2020) on health-related quality of life.

In contrast to these studies, we evaluate health utilities in a German multicenter cohort of PLWHA who receive cART using the EuroQol instrument. The study is based on the data collected in a nationwide multi-centre, non-interventional, prospective 96-week survey conducted in PLWHA in Germany: "Cost and Resource Utilisation Study in Antiretroviral Therapy (CORSAR)". The survey has been previously described in a paper by Kuhlmann et al. who provide a summarization of the collected data for the 48-week period and report the costs and utility values across three therapy lines(Kuhlmann et al., 2015). Another study thoroughly examines and describes the cost data of CORSAR(Treskova et al., 2016). The present study reports the HRQoL data collected over the whole period of the survey in greater detail and identifies influential clinical and therapy-related factors.

\section{Methods}

\section{Study Population}

Inclusion criteria for CORSAR were broadly defined: (i) HIV positive diagnosis, (ii) age of at least 18 years, and (iii) receiving cART at the study entry. The survey was not intended to include primary treatment, i.e. naïve patients. The observation period was 96 weeks between April 2009 (the first patient started) and April 2012 (the last patient finished) with scheduled quarterly visits at the involved physicians. The participating 
physicians from the four hospitals and eight private practices specialized in HIV went through a six-month preparation period with baseline examinations. Overall, the CORSAR study population included 1154 PLWHA.

The self-reported questionnaires and electronic clinical records were used to collect the data. The dataset includes socio-demographical characteristics (age, gender, education, employment), HIV- and general health-related records (CD4 cell count, viral load, disability, comorbidities, conditions, results of laboratory tests), details of diagnosis (time after the initial diagnosis of HIV infection, CDC category) and records of the antiretroviral therapy (line of antiretroviral regimen at the start of the study, medications, genotypic resistance tests).

\section{Measurement of Quality of Life}

In CORSAR, the preference-based EQ-5D-3L self-reported questionnaire was employed for measurement of HRQoL. EQ-5D contains the descriptive system and the visual analogue scale (VAS). The EQ-5D-3L descriptive system comprises five domains (mobility, self-care, usual activities, pain/physical discomfort, anxiety/ depression). Each domain was assessed by the patients using in three levels of perceived problems (none, moderate, severe). Different combinations of the recorded levels for the five areas were weighted based on the preferences identified by the general population for which the tariffs from Germany were used. This weighted utility summary score is further referred to as (TTO) utility value.

The EQ-VAS is a scale reaching from 0 to 100 (worst imaginable health state - best imaginable health state) on which patients mark how good or bad they assess their current health. This scale is another measure of HRQoL. In CORSAR, the participants were asked to fill out the questionnaires at all visits. For the following analyses, only those participants were included who completed the EQ-5D-3L questionnaire.

\section{Ethical Review}

The CORSAR survey was approved by the national regulatory authorities and local ethics committees of all participating centres. All patients were given thorough information on the survey. Before the participation in the interviews, the patients provided written consent. No incentive was offered to the patients for their participation in the survey.

\section{Data Analyses}

Descriptive and regression analyses were carried out. The descriptive analysis was based on the data collected at the beginning of the study. The regression analysis was performed to explore the factors which were associated with differences in HRQoL in PLWHA. The data collected at the beginning of the study, and during the follow-up visits were used. Generalized linear models (GLMS) were fitted using a three-parameter beta-inflated distribution for the TTO utility values and a four-parameter beta-inflated distribution for the VAS HRQoL values. This distribution type accounts for the nature of the quality of life measures being bound between the values zero and one. The selection of the predictor variables was based on expert opinion and a systematic review of relevant factors on quality of life of HIV patients(Degroote et al., 2014). 
The regression model included socio-demographic variables (age, gender, education and job), HIV-related variables (CD4 cell count, viral load, CDC group, years since the first HIV diagnosis), cART-related variables (regimen, duration, number of changes during the survey), and comorbidity. The measurements of quality of life, CD4 cell counts, viral load, cART regimen (with start and end date), comorbidity, education and job were taken for each participant at three months interval. These records were included in the model for each participant who had done at least five visits. In order to account for the fact that repeated measures taken from the same person can be correlated, we included the random effect of the participant ID into the model (see model specification in the supplement, File 1).

For the variables representing education, job, and cART regimen, the categories were grouped to reduce the factor levels. For education, patients with no or other education and secondary school (grade 9) were summarised into one category, and high school and university were clustered together. Middle school (grade 10) and patients with vocational training remained at a single level, respectively. For job, employment statuses "house", "studying", "other" and "unemployed" were grouped into one category as well as "self-employed" and "part-time work" were united. CD4 cell counts were grouped into levels " $<200$ cells/ $\mu \mathrm{L}$ ", "200-499 cells/ $\mu \mathrm{L}$ ", and " $\geq 500$ cells $/ \mu \mathrm{L}$ ". Viral load was categorized in four levels representing "below quantification limit", "<10.000", "10,000-100,000", and " $\geq 100,000 "$ "

For cART treatment, if the data were available, the cART regimen were ordered based on the dates of the start and the end of the treatment. Using these dates duration (in years) of respective treatment was calculated. Assignment of the TTO and VAS values to the regimen and the duration was performed based on the comparison of the start and the end dates to the date of the visit.

Classes of the antiretroviral regimens were categorized into three groups, according to the treatment status of a patient and following the existing German treatment guidelines: "standardized" and "individualized". "Standardized" regimens included either NNRTI (non-nucleoside reverse transcriptase inhibitor)-based regimen, consisting of one NNRTI in addition to nucleos(t)ide analogues, or PI (Protease inhibitor)-based regimen, consisting of one ritonavir-boosted $\mathrm{PI}(\mathrm{PI} / \mathrm{r})$ in addition to nucleos(t)ide (NRTI) analogues(Deutsche AIDS-Gesellschaft, 2012). "PI-individualized" class was assigned to the PI/r-based cART regimens in patients with a history of multiple treatment failures and acquiring multi-resistant HIV. "Other" cART regimens did not meet the criteria of the NNRTI and PI-based regimen and were based on the INSTI (integrase strand transfer inhibitor) raltegravir or the CCR5 (C-C chemokine receptor type 5) inhibitor maraviroc, or nuke-sparing regimens, for example, boosted double PI/r therapy. The cART regimens used in the survey are summarised in Table S3 in the supplement.

All metric variables were transformed to z-scores by subtracting their mean and dividing by their standard deviation. VAS score was divided by 100 to transform it to an outcome comparable to the TTO utility values. A random intercept was included to capture the hierarchical structure of the data. All analyses were carried out using $\mathrm{R}$ software (version 3.4) and the gamlss package and the random() function for the random intercept. In order to detect possible collinearity, varianceinflation factors were calculated using vif() function of the car package (see supplement, File 1). 


\section{Results}

\section{Study Population}

Out of the recruited 1154 patients, 1056 completed the EQ-5D-3L questionnaires at the first visit (further baseline). The number of the completed questionnaires varied from 808 to 667 during the follow-up. This descriptive analysis is based on the records of 1056 patients. The data for all follow-up visits are summarized in the supplemental Tables (S1 and S2). Table 1 presents the socio-demographic and the clinical characteristics of the participants who completed the questionnaires at baseline). The sample encloses mostly male HIV-infected patients (88.8\%) and those in the 30-60 age group $(82.7 \%)$. Majority of the participants have school-level education $(70.7 \%)$ and have a steady income: employed (39.6\%) and retired (22.8\%). At baseline, $42 \%$ of the participants were listed in category CDC-B (symptomatic HIV infection), 28.6\% were in category CDC-A (asymptomatic HIV infection), and $27.1 \%$ were in category CDC$\mathrm{C}$ (AIDS-indicator). Majority of the participants had CD4 counts over 200cells $/ \mu \mathrm{L}$ (93.5\%) and HIV viral load below quantification limit (less than 50 copies $/ \mathrm{mL}, 89.9 \%$ ) at baseline. $82.6 \%$ of the participants had comorbidities. Of them, 58 patients had lipodystrophy, 13 - diabetes mellitus, 35 - Hepatitis C, 52 - Hepatitis B, and 8 participants had depression (see S1 in supplement). These conditions were observed separately from other comorbidities. Other comorbidities were categorized into groups which are presented in Table 1 . The table also gives the clinical characteristics of the patients for other visits. At baseline, most of the patients received PI-based regimens (516 patients) and NNRTI-based regimens (292 patients).

\section{Estimation of Utility Values and HRQoL Values}

Table 2 summarises the most reported health states at baseline, the recorded levels for the five EQ-5D areas and mean and standard deviations for TTO utility scores and HRQoL VAS scores (see Table S4 for all visits in the supplement). For the total sample, the mean TTO score is $0.912( \pm 0.154)$ with $59.3 \%$ ranging from 0.9 to 1.0 , and the mean VAS score is $84.32( \pm 18.55)$ with $54.5 \%$ ranging from 90 to 100 . For the five EQ-5D domains, most patients report "no problems" in the "mobility" (83.8\%) and "self-care" (97.7\%). In contrast, in the areas "emotional health" and "physical discomfort" a large part of the patients reports "some problems" (24\% and 32\% respectively). Additionally, Table 3 presents the mean estimates of TTO utility values by CDC category, age group, group of years since HIV diagnosis and cART regimen (at baseline records).

Mean estimate of the TTO utility values at baseline for the patients who have AIDS (listed in CDC class C) lower than for people who have no AIDS. The descriptive analysis of utility values across age groups does not allow the conclusion that health state utilities decrease in older people. The variation for CDC category A is between 0.927 (40-49 year olds (yo)) and $1.00(<20$ yo) and for CDC B is 0.963 (20-29yo) 0.889 (50-59yo). For CDC category $\mathrm{C}$, the older people seem to have worse utility vales with a range of 0.934 (20-29 yo) -0.855 ( $>60$ yo). The consideration of cART regimen suggests higher utility values for PI-based regimen than for NNRTI-based regimen in the patients listed in $\mathrm{CDC}$ categories B and C. Analysis of mean estimates of 
Table 1 Socio-demographic and clinical characteristics of the patients in CORSAR. $(n=$ participants who completed EQ-5D-3L questionnaires at baseline)

\begin{tabular}{|c|c|c|c|c|c|}
\hline \multirow{2}{*}{$\begin{array}{l}\text { Socio-demographic Characteristics } \\
\text { Age (mean. SD) }\end{array}$} & \multicolumn{2}{|c|}{$\begin{array}{l}\text { at Visit } 0 \\
\text { (Baseline) } \\
(\mathrm{n}=1056)\end{array}$} & \multirow{2}{*}{$\begin{array}{l}\text { Clinical Characteristics } \\
\begin{array}{c}\text { Years since diagnosis of HIV } \\
\text { (mean. SD) }\end{array}\end{array}$} & \multicolumn{2}{|c|}{$\begin{array}{l}\text { at Visit } 0 \\
\text { (Baseline) } \\
(\mathrm{n}=1056)\end{array}$} \\
\hline & 47.6 & 11.0 & & 10.7 & 7.0 \\
\hline Age (n.\%) & & & $\begin{array}{l}\text { HIV infection stage (CDC } \\
\text { classification) (n. \%) }\end{array}$ & & \\
\hline$<20$ years old & 1 & 0.1 & Asymptomatic (Category A) & 302 & 28.6 \\
\hline 20-29 years old & 43 & 4.1 & Symptomatic (Category B) & 443 & 42 \\
\hline 30-39 years old & 207 & 19.6 & AIDS-Indicator (Category C) & 286 & 27.1 \\
\hline $40-49$ years old & 444 & 42 & Not recorded & 25 & 2.4 \\
\hline $50-59$ years old & 223 & 21.1 & CD4+ cell count (n. \%) & & \\
\hline$>60$ years old & 138 & 13.1 & $<200$ cells $/ \mu \mathrm{L}$ & 65 & 6.2 \\
\hline Gender (n.\%) & & & $200-499$ cells $/ \mu \mathrm{L}$ & 402 & 38.1 \\
\hline Male & 938 & 88.8 & $\geq 500$ cells $/ \mu \mathrm{L}$ & 585 & 55.4 \\
\hline Female & 112 & 10.6 & Not recorded & 4 & 0.4 \\
\hline Transsexual & 6 & 0.6 & $\begin{array}{l}\text { HIV viral load (different grouping) } \\
\quad \text { (n. \%) }\end{array}$ & & \\
\hline Education level (n.\%) & & & Below quantification limit & 949 & 89.9 \\
\hline No qualifications & 88 & 8.3 & $<10.000$ & 90 & 8.5 \\
\hline $\begin{array}{l}\text { Secondary school leaving certificate (leaving } \\
\text { after 9th grade) }\end{array}$ & 243 & 23 & $10.000-100.000$ & 7 & 0.7 \\
\hline $\begin{array}{l}\text { Intermediate school-leaving certificate (leaving } \\
\text { after 9th grade) }\end{array}$ & 308 & 29.2 & $\geq 100.000$ & 6 & 0.6 \\
\hline $\begin{array}{l}\text { School diploma corresponding to university } \\
\text { entrance level }\end{array}$ & 195 & 18.5 & Not recorded & 4 & 0.4 \\
\hline Professional training & 86 & 8.1 & Comorbidity (n. \%) & & \\
\hline University & 115 & 10.9 & Presence of comorbidity & 872 & 82.6 \\
\hline Other & 3 & 0.3 & $1-4$ conditions & 655 & 62 \\
\hline No response & 88 & 8.3 & $>5$ conditions & 216 & 20.5 \\
\hline Employment status (n. \%) & & & Allergy & 188 & 17.8 \\
\hline Full-time employed & 418 & 39.6 & Dermatological & 286 & 27.1 \\
\hline Part-time employed & 77 & 7.3 & Respirational & 183 & 17.3 \\
\hline Self-employed & 73 & 6.9 & Cardiovascular & 248 & 23.5 \\
\hline Unemployed & 95 & 9 & Endocrine & 134 & 12.7 \\
\hline Retired & 241 & 22.8 & Gastro-intestinal & 249 & 23.6 \\
\hline House & 17 & 1.6 & Haematological & 89 & 8.4 \\
\hline In study & 10 & 0.9 & Neurological & 145 & 13.7 \\
\hline Other & 17 & 1.6 & Psychiatric & 209 & 19.8 \\
\hline No response & 108 & 10.2 & Other & 601 & 56.9 \\
\hline
\end{tabular}

TTO utility values by the "years since HIV" groups suggests worsening of quality of life with time. Figure 1 illustrates TTO utility values plotted against the variable "years since HIV-diagnosis" for the whole sample. 
Table 2 Records of measurement of quality of life of the patients in CORSAR at baseline $(n=1056)$

Most reported health states at baseline (n.\% of total)
EQ-5D-3L domains and levels (n.\%)

\begin{tabular}{lllllll}
\hline 11,111 & 479 & 45.4 & Mobility & None & 885 & 83.8 \\
11,112 & 111 & 10.5 & & Some & 171 & 16.2 \\
11,121 & 96 & 9.1 & & Severe & 0 & 0 \\
11,122 & 96 & 9.1 & Self-care & None & 1032 & 97.7 \\
11,212 & 13 & 1.2 & & Some & 23 & 2.2 \\
11,221 & 16 & 1.5 & & Severe & 1 & 0.1 \\
11,222 & 46 & 4.4 & Usual activities & None & 857 & 81.2 \\
21,121 & 26 & 2.5 & & Some & 187 & 17.7 \\
21,122 & 21 & 2 & & Severe & 12 & 1.1 \\
21,221 & 20 & 1.9 & Pain/discomfort & None & 632 & 59.8 \\
21,222 & 36 & 3.4 & & Some & 395 & 37.4 \\
TTO value mean, SD & 0.912 & 0.154 & & Severe & 29 & 2.7 \\
& & & Anxiety/depression & None & 664 & 62.9 \\
VAS value mean. SD & 84.32 & 18.55 & & Some & 366 & 34.7 \\
& & & & Severe & 26 & 2.5 \\
\hline
\end{tabular}

\section{Driving Factors}

The results of the explanatory models of health state utilities and HRQoL are given in Table 4. For the regression analysis, the dataset was restricted to the patients with available observations for all variables included in the regression model and contained 3436 observations, that is for 791 participants.

The probability function of the inflated beta distribution is defined by three parameters, $f_{Y}=(y \mid \mu, \sigma, \nu)$, in case the outcome variable takes values in the interval $(0,1]$ and four parameters, $f_{Y}=(y \mid \mu, \sigma, \nu, \tau)$, if the interval is [0,1] (Stasinopoulos, 2017). The former is the case for the TTO values, and the latter is for VAS values in the analyzed dataset. The distributions of the VAS and TTO values are presented in the supplement (File 1, Fig. 1). The intercepts of 2.28 for TTO and 1.43 for VAS correspond to a utility value of 0.907 and VAS score of 81.4, given all metric variables being at their mean and categorical variables taking the reference values: male patient with a high-school or university education and full-time employment, in CDC category A, a viral load below the quantification limit and PI-based treatment. Further, we focus more on the TTO outcomes as the results of the GLM for VAS scores can be similarly analyzed.

All coefficients should be interpreted in relation to this reference case. Starting with the socio-demographic variables, each increase of the age by one standard deviation decreases the estimate of utility value. No significant difference in the estimates was detected for transgender patients, but women show a significantly higher utility value of 0.926. Compared to persons with university-level or high school education, patients with lower educational levels have lower utility values, particularly, the people with vocational training. In the context of occupational levels, part-time- and self-employed persons show a slightly decreased utility value of 0.894 compared to full-time 
Table 3 TTO utility values (mean, SD) across CDC categories and by age group, years living with HIV and cART regimen at baseline $(n=1056)$

\begin{tabular}{|c|c|c|c|c|c|c|}
\hline \multirow{3}{*}{$\begin{array}{l}\text { C D C } \\
\text { category }\end{array}$} & \multicolumn{6}{|c|}{ TTO utility values (mean, SD) } \\
\hline & \multicolumn{6}{|l|}{ Age groups } \\
\hline & $<20$ & $20-29$ & $30-39$ & $40-49$ & $50-59$ & $>60$ \\
\hline CDC-A & 1.000, na & $0.980,0.044$ & $\begin{array}{l}0.951 \\
0.101\end{array}$ & $\begin{array}{l}0.927 \\
0.129\end{array}$ & $\begin{array}{l}0.941 \\
0.108\end{array}$ & $0.946,0.136$ \\
\hline CDC-B & na & $0.963,0.070$ & $\begin{array}{l}0.935 \\
0.140\end{array}$ & $\begin{array}{l}0.901 \\
0.167\end{array}$ & $\begin{array}{l}0.889 \\
0,173\end{array}$ & $0.919,091$ \\
\hline CDC-C & na & $0.934,0.076$ & $\begin{array}{l}0.928 \\
0.157\end{array}$ & $\begin{array}{l}0.892 \\
0.178\end{array}$ & $\begin{array}{l}0.857 \\
0.181\end{array}$ & $0.855,0.244$ \\
\hline \multirow{2}{*}{$\begin{array}{l}\text { CDC } \\
\text { category }\end{array}$} & \multicolumn{6}{|c|}{ Years living with HIV } \\
\hline & \multicolumn{2}{|c|}{$<10$} & \multicolumn{2}{|l|}{$10-20$} & \multicolumn{2}{|l|}{$>20$} \\
\hline CDC-A & \multicolumn{2}{|l|}{$0.960,0.081$} & \multicolumn{2}{|l|}{$0.928,0.151$} & \multicolumn{2}{|l|}{$0.846,0.146$} \\
\hline CDC-B & \multicolumn{2}{|l|}{$0.911,0.167$} & \multicolumn{2}{|l|}{$0.922,0.112$} & \multicolumn{2}{|l|}{$0.882,0.145$} \\
\hline $\mathrm{CDC}-\mathrm{C}$ & \multicolumn{2}{|l|}{$0.914,0.179$} & \multicolumn{2}{|l|}{$0.882,0.154$} & \multicolumn{2}{|l|}{$0.818,0.241$} \\
\hline \multirow{2}{*}{$\begin{array}{l}\text { CDC } \\
\text { category }\end{array}$} & \multicolumn{6}{|l|}{$c A R T$ regimen } \\
\hline & $\begin{array}{l}\text { NNRTI } \\
\text { individ. }\end{array}$ & $\begin{array}{l}\text { NNRTI } \\
\text { standard. }\end{array}$ & PI individ. & PI standard. & Other & $\begin{array}{l}\text { Therapy } \\
<14 \text { days }\end{array}$ \\
\hline CDC-A & $0.943,0.065$ & $0.946,0.133$ & $\begin{array}{l}0.931 \\
0.073\end{array}$ & $\begin{array}{l}0.922, \\
0.131\end{array}$ & $\begin{array}{l}0.962 \\
0.081\end{array}$ & $0.962,0.065$ \\
\hline CDC-B & $0.866,0.101$ & $0.902,0.162$ & $\begin{array}{l}0.871 \\
0.210\end{array}$ & $\begin{array}{l}0.913 \\
0.150\end{array}$ & $\begin{array}{l}0.928 \\
0.121\end{array}$ & na \\
\hline CDC-C & $0.662,0.287$ & $0.874,0.204$ & $\begin{array}{l}0.829 \\
0.230\end{array}$ & $\begin{array}{l}0.896 \\
0.148\end{array}$ & $\begin{array}{l}0.942 \\
0.141\end{array}$ & $0.944,0.080$ \\
\hline
\end{tabular}

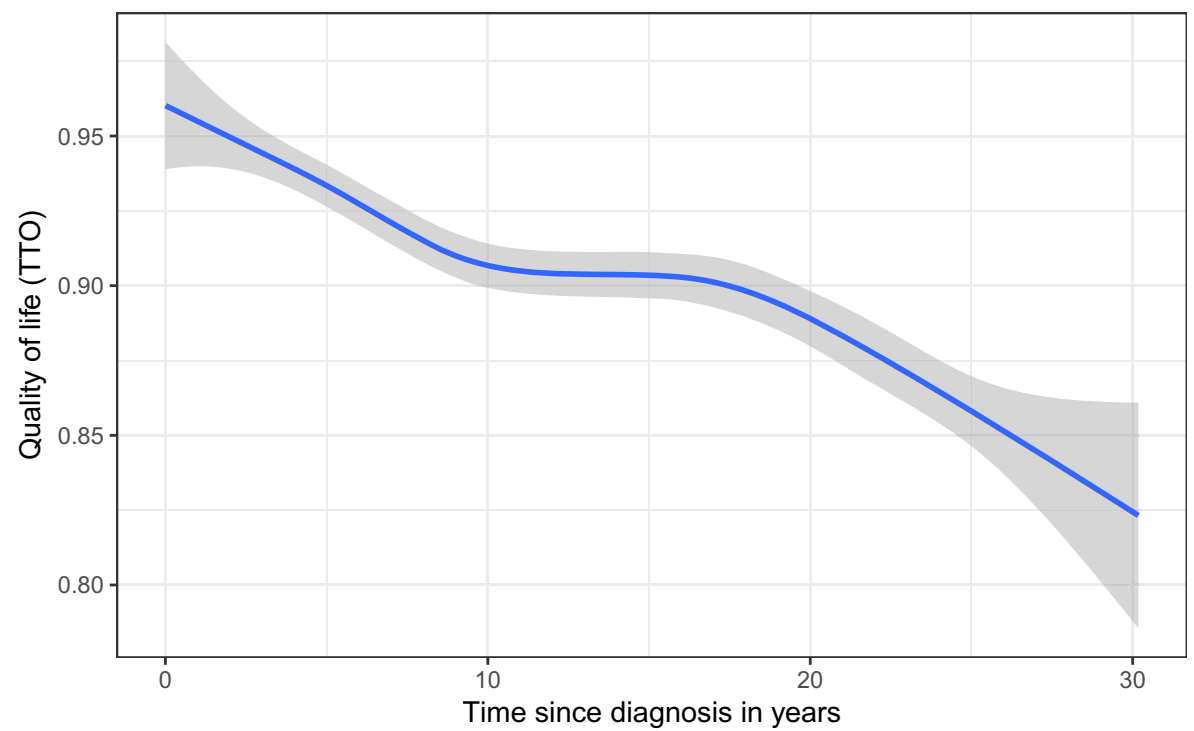

Fig. 1 TTO utility values in dependence on time living with HIV (years) 
Table 4 Results of the GLM model of the analysis of TTO values and VAS scores via a beta-inflated distribution

\begin{tabular}{|c|c|c|}
\hline Variables & TTO Model & VAS Model \\
\hline \multicolumn{3}{|l|}{ Mu (logit-link) } \\
\hline Intercept & $2.28(0.06)^{* * * *}$ & $1.48(0.02)^{* * * *}$ \\
\hline Age in years (z-score) & $-0.02(0.02)$ & $-0.06(0.01)^{* * *}$ \\
\hline Gender: male & Reference & Reference \\
\hline Gender: female & $0.26(0.06)^{* * *}$ & $0.00(0.05)$ \\
\hline Gender: transsexual & $0.38(0.36)$ & $-0.14(0.15)$ \\
\hline Education: high school/university & Reference & Reference \\
\hline Education: none/other/secondary school & $-0.18(0.05)^{* * * *}$ & $-0.01(0.02)$ \\
\hline Education: junior high school & $-0.33(0.05)^{* * * *}$ & $-0.14(0.02)^{* * *}$ \\
\hline Education: vocational training & $-0.47(0.06)^{* * * *}$ & $-0.20(0.03)^{* * *}$ \\
\hline Job: Full-time employment & Reference & Reference \\
\hline Job: House/Student/Other/Unempl & $-0.27(0.06)^{* * *}$ & $-0.37(0.03)^{* * *}$ \\
\hline Job: Self-empl/Part-time & $-0.14(0.06)^{*}$ & $-0.02(0.02)$ \\
\hline Job: Retirement & $-0.28(0.05)^{* * *}$ & $-0.17(0.02)^{* * *}$ \\
\hline Years with HIV (z-score) & $-0.14(0.02)^{* * *}$ & $-0.13(0.01)^{* * *}$ \\
\hline CDC Group A & Reference & Reference \\
\hline CDC Group B & $-0.01(0.05)$ & $-0.07(0.02)^{* * *}$ \\
\hline CDC Group C & $-0.06(0.05)$ & $0.11(0.02)^{* * * *}$ \\
\hline CD4 cell count $\geq 500 / \mu \mathrm{L}$ & Reference & Reference \\
\hline CD4 cell count $200-499 / \mu \mathrm{L}$ & $-0.08(0.04)$ & $-0.06(0.02)^{* * *}$ \\
\hline CD4 cell count $<200$ & $-0.26(0.08)^{* *}$ & $-0.45(0.04)^{* * *}$ \\
\hline Viral load below the quantification limit & Reference & Reference \\
\hline Viral load $<10,000$ & $0.07(0.07)$ & $-0.01(0.04)$ \\
\hline Viral load 10,000 - 100,000 & $0.25(0.26)$ & $-0.24(0.13)$ \\
\hline Viral load $>100,000$ & $0.67(0.48)$ & $0.27(0.27)$ \\
\hline cART: PI-based & Reference & Reference \\
\hline cART: NNRTI-based & $-0.04(0.05)$ & $0.04(0.02)$ \\
\hline cART: in change & $-11.02(25.89)$ & 1.44 \\
\hline cART: Other & $0.11(0.05)^{*}$ & $0.27(0.02)^{* * *}$ \\
\hline cART: Duration in years (z-score) & $0.01(0.03)$ & $-0.00(0.02)$ \\
\hline Number of treatment changes (z-score) & $-0.06(0.02)^{* * *}$ & $-0.08(0.01)^{* * *}$ \\
\hline Number of co-morbidities (z-score) & $-0.13(0.02)^{* * *}$ & $-0.10(0.01)^{* * *}$ \\
\hline Lipodystrophy & $0.01(0.07)$ & $0.03(0.04)$ \\
\hline Diabetes & $0.69(0.17)^{* * *}$ & $0.13(0.07)^{*}$ \\
\hline Hepatitis C & $-0.01(0.11)$ & $-0.24(0.05)^{* * *}$ \\
\hline Hepatitis B & $0.04(0.09)$ & $0.11(0.05)^{*}$ \\
\hline Depression & $-0.97(0.40)^{*}$ & $-0.61(0.23)^{* *}$ \\
\hline \multicolumn{3}{|l|}{ Interaction terms: } \\
\hline cART NNRTI-based:Duration & $-0.02(0.04)$ & $-0.05(0.02)^{*}$ \\
\hline cART in change:Duration & $-9.08(19.87)$ & 1.20 \\
\hline cART in change:Other & $-0.05(0.04)$ & $0.01(0.03)$ \\
\hline
\end{tabular}


Table 4 (continued)

\begin{tabular}{|c|c|c|}
\hline Variables & TTO Model & VAS Model \\
\hline \multicolumn{3}{|l|}{ Sigma (logit-link) } \\
\hline Intercept & $-0.83(0.04)^{* * * *}$ & $-1.38(0.03)^{* * * *}$ \\
\hline CD4 cell count $200-499 / \mu \mathrm{L}$ & $-0.25(0.05)^{* * * *}$ & $-0.10(0.03)^{* *}$ \\
\hline CD4 cell count $<200$ & $-0.23(0.10)^{*}$ & $-0.11(0.05)^{*}$ \\
\hline CDC Group B & $0.18(0.05)^{* * *}$ & $0.02(0.03)$ \\
\hline CDC Group C & $0.20(0.06)^{* * * *}$ & $-0.01(0.04)$ \\
\hline cART: Duration in years (z-score) & $-0.14(0.02)^{* * * *}$ & $-0.01(0.00)^{* * * *}$ \\
\hline \multicolumn{3}{|l|}{$\mathrm{Nu}($ logit-link) } \\
\hline Intercept & $0.03(0.06)$ & $-5.39(0.64)^{* * *}$ \\
\hline CD4 cell count $200-499 / \mu \mathrm{L}$ & $0.15(0.07)^{*}$ & -16.08 \\
\hline CD4 cell count $<200$ & $-0.39(0.18)^{*}$ & $-15.73(215.12)$ \\
\hline CDC Group B & $-0.33(0.08)^{* * * *}$ & -17.46 \\
\hline CDC Group C & $-0.38(0.09)^{* * * *}$ & $-16.77(16.11)$ \\
\hline cART: Duration in years (z-score) & $-0.04(0.03)$ & $-0.82(0.78)$ \\
\hline \multicolumn{3}{|l|}{ Tau (logit-link) } \\
\hline Intercept & & $-3.39(0.18)^{* * * *}$ \\
\hline CD4 cell count $200-499 / \mu \mathrm{L}$ & & $-0.06(0.20)$ \\
\hline CD4 cell count $<200$ & & -0.05 \\
\hline CDC Group B & & $-0.17(0.25)$ \\
\hline CDC Group C & & $0.45(0.21)^{*}$ \\
\hline cART: Duration in years (z-score) & & -0.01 \\
\hline Number of observations & 3436 & 3436 \\
\hline Nagelkerke $\mathrm{R}^{2}$ & 0.45 & 0.75 \\
\hline Generalized AIC & 402.56 & -5730.14 \\
\hline
\end{tabular}

The mu parameter of the beta distribution corresponds to the mean TTO utility and VAS value ${ }^{* * *} p<0.001,{ }^{* *} p<0.01,{ }^{*} p<0.05$

The estimation of the coefficients of the sigma parameter indicates which variables are associated with the variance of TTO utilities and VAS score. The nu-parameter has to be seen differently for the models. For the TTO model, the nu-parameter reflects the probability of TTO utility taking value 1 . For the VAS model, the nu-parameter models the probability when the VAS score takes value 0 . The tau-parameter reflects the probability of a VAS score of 1 . It is only estimated in the VAS model because VAS scores are distributed in the interval $[0,1]$ which is approximated using the four-parameter beta inflated distribution

employed. Persons in the categories "house/studying/other/unemployed" and "retired" show a similar decrease in utility reaching 0.881 .

Regarding the HIV-related variables, the results show significant differences only in two variables: years living with HIV and CD4 cell count. An increase of 6.8 years above the mean of 10.3 years corresponds to a lower utility value of 0.894 . The CD4 cell count below 200cells/ $\mu \mathrm{L}$ (indicating immunological AIDS) also decreases utility compared to the CD4 cell count over 500 cells $/ \mu \mathrm{L}$ to 0.883 . The utility model suggests no significant differences between the viral load levels comparing to "below quantification limit".

The group of variables which captures the cART-related factors shows that treatment with "other" regimen (i.e. which is not NNRTI- or PI-based) increases utility 
(0.916) compared to treatment with the PI-based regimen. The number of changes in the treatment regime shows a significant association with utility. The coefficient suggests that utility value is lower for an above-average number of treatment changes. Duration of treatment, i.e. time on cART, shows no signification association with TTO utility.

The comorbidities of the patients further influence the quality of life. The aboveaverage number (2.6) of comorbidities decreases utility. Lipodystrophy, hepatitis B and hepatitis $\mathrm{C}$ show no significant association with utility values. Patients with diabetes seem even to have a higher utility value. On the other hand, patients with depression have a lower utility value of 0.788 .

The results of GLM for the scores of the visual analogue scale demonstrate more significant differences for the tested categories compared to the reference case, particularly for the HIV-related variables. Comparing to CDC group A, CDC group B shows a decreasing effect and CDC group $\mathrm{C}$ an increasing effect on the VAS response. CD4 cell count $200-499$ cells $/ \mu \mathrm{L}$ shows a significant decrease in the VAS values and count below 200 cells $/ \mu \mathrm{L}$ demonstrates even a more substantial reduction in the VAS score comparing to the level $>500$ cells $/ \mu \mathrm{L}$. Other variables, which have significant differences to the reference case, show the same trends in VAS scores as in the TTO values with differences in the magnitude.

The results suggest that variance is smaller for the CD4 cell count groups 200-499 cells $/ \mu \mathrm{L}$ and $<200$ cells $/ \mu \mathrm{L}$ comparing to $>500$ cells $/ \mu \mathrm{L}$, i.e. the patients with $>500$ CD4 cells $/ \mu \mathrm{L}$ show greater variance in their TTO and VAS values than those two groups. The variance of TTO values is greater for the CDC groups $\mathrm{C}$ and $\mathrm{B}$ compared to $\mathrm{CDC}$ group A. Also longer duration of regimen seems to be associated with a lower variance of TTO and VAS outcomes.

CDC group and CD4 cell count group are significantly associated with the probability of TTO utility having value 1 . Decreased CD4 cell count and CDC groups B and $\mathrm{C}$ lower this probability. For the VAS model, these variables did not show significant effects, but CDC group $\mathrm{C}$, which is associated with an increased probability of VAS score taking value 0 .

\section{Discussion}

This study provides an analysis of quality of life data collected in a major observational study undertaken between 2009 and 2012 in people living with HIV and AIDS in Germany. This multi-centric, nationwide study includes a large cohort by working with the main healthcare providers for PLWHA and provides a representative population to study HRQoL.

The results suggest that the mean EQ-VAS value obtained in this study (84.3) is comparable with EQ-VAS estimated for the general population in 2009 (79.2)(Mielck et al., 2010). However, based on the reported characteristics of the sample representing the general population, it is difficult to explain why the self-reported quality of life in the patients of CORSAR is higher than that of the general population.

This study shows that the most affected dimensions of quality of life are "anxiety/ depression" and "pain/physical discomfort", while "mobility" and "self-care" are minor problems. This supports the preliminary results from Investigation on Antiretroviral 
Therapy (IANUA) and highlights the need to improve specific psychological and social support for PLWHA(Venturini et al., 2014).

In order to distinguish the effects of different patient characteristics, we conducted a regression analysis using a GLM with beta-inflated distributions. Among the sociodemographic factors, when the clinical and treatment variables were controlled for, higher education, being full-time employed, and female gender were significantly associated with better HRQoL. The employment and higher education possibly facilitate a better mental state contributing to the HRQoL difference. Women also were suggested to have better coping strategies (Ruiz Perez et al., 2005; Zinkernagel et al., 2001). Depression was demonstrated to have a significant decreasing impact on TTO utility values. The findings support the importance of mental health assessment in the management of HIV-disease.

Our findings indicate that time since diagnosis is associated with lower HRQoL. This may support the previously stated assumption that people who live long with HIV experience accumulated adverse effects in HRQoL(Bing et al., 2000; Zinkernagel et al., 1999).

The results show decreased TTO utilities and self-assessed values for the patients in CD4-T cell group $<200$ cells $/ \mu \mathrm{L}$. This finding can be intuitive, for an untreated HIV infection, which progresses to a further stage, diminishes physical health and impairs quality of life. Indeed, the poorest physical health is observed in people whose HIV has progressed to AIDS(Préau, Marcellin, et al., 2007a). The study supports the recent development of treatment guidelines which recommend the initiation of cART even in asymptomatic patients with normal CD4-T cell counts (Lundgren et al., 2015). In contrast, Jia et al. showed that a higher CD4-T cell count was associated with worse HRQoL at baseline, but the same CD4-T cell counts were predictive of higher HRQoL scores 12 months later(Jia et al., 2007). Though this finding may be counter-intuitive, it is possible that the initial psychological impact of a high CD4-T cell count is significant, but over time PLWHA may more readily accept a high CD4-T cell count and are less likely to experience changes in HRQoL based on this specific factor.

The analysis did not found a significant effect of duration of therapy on the HRQoL, but an increased number of changes of therapy was significantly associated with decreased TTO and VAS values. This study did not reveal a differential impact between NNRTI- and PI-based regimens, supporting the national guidelines of the German AIDS Association(Deutsche AIDS Gesellschaft, DAIG)(Deutsche AIDS-Gesellschaft, 2012), which allows physicians to choose between a broad spectrum of available options of cART. The German policy is distinct from most international guidelines, giving physicians the opportunity to personalize the treatment, adapting cART regimens based on individual patients' reactions. An administrative database analysis of approximately four million beneficiaries showed that German physicians use this flexibility and are more likely to prescribe patients who are in a more advanced disease state (CDC class $\mathrm{C}$ ) with a PI/r-based regimen than with an NNRTI-based regimen(Mahlich et al., 2015). The same result was obtained in another observational study in Germany(Mahlich et al., 2016).

\section{Limitations}

This observational study did not predefine endpoints and is not statistically powered for more extensive subgroup-analyses. The comparison between the cART regimens may be confounded by indication because the studied population included PLWHA at 
different treatment lines (naïve and experienced). The regression analysis shows the impact of comorbidity on HRQoL in PLWHIV, which requires further investigation. The number of observations for diabetes and hepatitis might be not sufficient to detect differences in the utilities. Further, the study utilized the EQ-5D questionnaire, which is a "non-disease-specific instrument". Although it allowed estimating quality of life weights applicable for health economic evaluations, it may be a relatively insensitive tool for measuring the specific HRQoL in PLWHA. Future studies should test the robustness of our results with alternative instruments such as HIV-specific questionnaires like the WHOQOL-HIV Instrument(World Health Organization, 2002). Finally, the study period occurred before the integrase strand transfer inhibitors (INSTI) elvitegravir and dolutegravir became available, which are meanwhile widely used as components of cART in Germany.

\section{Conclusions}

As long as HRQoL in PLWHA shows variations across the socio-demographic and the clinical characteristic of individuals, measuring HRQoL and determining factors affecting HRQoL can help to understand to what extent HRQoL is affected by the infection and cART treatment. This analysis used the EQ-5D-3L measurement of utility values (quality of life weights) and determined the factors which influence on HRQoL. The results of this study can inform the development and evaluation of HIVrelated intervention strategies to improve health-related quality of life in people living with HIV and AIDS in Germany.

Abbreviations AIDS, acquired immune deficiency syndrome; $A R V$, Antiretroviral; $c A R T$, combination antiretroviral therapy; $C D C$, Centers for Disease Control and Prevention classification system; CORSAR, Cost and Resource Utilization Study in Antiretroviral Therapy; EQ-5D, EuroQol five dimensions questionnaire; $E Q-5 D-3 L$, EuroQol five dimensions questionnaire three-level scale; $G L M$, generalized linear model; $H I V$, the human immunodeficiency virus; $H R Q o L$, health-related quality of life; NNRTI, non-nucleoside reverse transcriptase inhibitor; PI, protease inhibitor; PLWHA, people living with HIV and AIDS; $Q A L Y$, quality-adjusted life year

Supplementary Information The online version contains supplementary material available at https://doi.org/ 10.1007/s11482-021-09939-1.

Acknowledgements The conducted survey resulted from valuable contributions made by a great team of medical professionals. We thank our colleagues, Martin Hower, Claudia Bachmann, Hans Heiken, Stephan Klauke, Johannes Bogner, Olaf Degen, Hans-Jürgen Stellbrink, Ingrid Leistner, Christian Träder, Birger Kuhlmann, Reinhold E. Schmidt, Stefan Reuter, Peter Gute, Dietrich Gorriahn, Britta Ranneberg and Jörn Wettach who greatly assisted the processes of patients' enrolment and data collection.

The authors thank all patients and the study centers for participating in the CORSAR survey:

1. ID-Ambulanz der Medizinischen Klinik Nord, Klinikum Dortmund, Dortmund.

2. Innere Medizin, Praxis Georgstraße, Hannover.

3. Infektiologie, Infektiologikum, Frankfurt.

4. Infektionskrankheiten und klinische Immunologie, Ludwig-Maximilians-Universität München, München. 
5. Infektiologie, Universitätsklinikum Hamburg-Eppendorf, Hamburg.

6. ICH Grindelstraße, Infektionsmedizinisches Centrum Hamburg, Hamburg.

7. Innere Medizin, Ärzteforum Seestraße, Berlin.

8. Klinik für Immunologie und Rheumatologie, Medizinische Hochschule Hannover, Hannover

Availability of Data and Material Please contact author for data requests.

Authors' Contributions MT carried out analysis and interpretation of data, the descriptive analysis, drafting and revision of the manuscript.

STS performed the statistical analyses, interpretation of data and revision of the manuscript.

AK carried out analysis and interpretation of data and revision of the manuscript.

JM participated in the study conception and design, drafting and revision of the manuscript.

MS carried out the study conception and design, participated in recruiting of the patients, conducted the study protocol and data collection, and participated in analysis and interpretation of data, drafting and revision of the manuscript.

Funding Open Access funding enabled and organized by Projekt DEAL. CORSAR study has been funded by an unrestricted Janssen-Cilag grant.

\section{Declarations}

Ethics Approval and Consent to Participate The CORSAR survey was approved by the national regulatory authorities and local ethics committees of all participating centres. All patients were given thorough information on the survey. Before the participation in the interviews, the patients provided written consent. No incentive was offered to the probands for their participation in the survey.

\section{Consent for Publication Not applicable.}

Competing Interests By the fact that the patients had been receiving cART before the enrollment into the study, the selection of cART regimen in the sample was not influenced by the authors.

MS has received honoraria as an advisor and lecturer in studies funded by Abbvie, Boehringer-Ingelheim, Bristol-Myers-Squibb, Gilead, Glaxo-Smith-Kline, Hexal, Janssen-Cilag, Merck Sharp \& Dohme, and ViiV Healthcare. He was a board member at Abbvie, Gilead Sciences, Hexal, Janssen-Cilag, and ViiV Healthcare. $\mathrm{JM}$ is an employee and stockholder at Janssen-Cilag GmbH, Johnson \& Johnson GmbH.

MT and AK declared no conflict of interest.

Open Access This article is licensed under a Creative Commons Attribution 4.0 International License, which permits use, sharing, adaptation, distribution and reproduction in any medium or format, as long as you give appropriate credit to the original author(s) and the source, provide a link to the Creative Commons licence, and indicate if changes were made. The images or other third party material in this article are included in the article's Creative Commons licence, unless indicated otherwise in a credit line to the material. If material is not included in the article's Creative Commons licence and your intended use is not permitted by statutory regulation or exceeds the permitted use, you will need to obtain permission directly from the copyright holder. To view a copy of this licence, visit http://creativecommons.org/licenses/by/4.0/.

\section{References}

Airoldi, M., Zaccarelli, M., Bisi, L., Bini, T., Antinori, A., Mussini, C., et al. (2010). One-pill once-a-day HAART: A simplification strategy that improves adherence and quality of life of HIV-infected subjects. In Patient preference and adherence, 4, 115-125.

Bing, E. G., Hays, R. D., Jacobson, L. P., Chen, B., Gange, S. J., Kass, N. E., Chmiel, J. S., \& Zucconi, S. L. (2000). Health-related quality of life among people with HIV disease: Results from the multicenter AIDS 
cohort study. In Quality of life research : an international journal of quality of life aspects of treatment, care and rehabilitation, 9(1), 55-63.

Brazier, J., Roberts, J., \& Deverill, M. (2002). The estimation of a preference-based measure of health from the SF-36. Journal of Health Economics, 21(2), 271-292.

Briggs, A, H., Claxton, K., Sculpher, M, J. (2011): Decision modelling for health economic evaluation. Oxford: Oxford University Press (Handbooks in health economic evaluation series). Available online at http://search.ebscohost.com/login.aspx?direct=true\&scope=site \&db=nlebk\&db=nlabk\&AN=1689059.

Briongos Figuero, L. S., Bachiller Luque, P., Palacios Martín, T., González Sagrado, M., \& Eiros Bouza, J. M. (2011). Assessment of factors influencing health-related quality of life in HIV-infected patients. HIV Medicine, 12(1), 22-30. https://doi.org/10.1111/j.1468-1293.2010.00844.x.

CADTH (2017): Guidelines for the economic evaluation of health technologies: Canada. Available online at https://www.cadth.ca/sites/default/files/pdf/guidelines_for_the_economic_evaluation_of_health_ technologies_canada_4th_ed.pdf, checked on 8/23/2019.

Call, S. A., Klapow, J. C., Stewart, K. E., Westfall, A. O., Mallinger, A. P., DeMasi, R. A., Centor, R., \& Saag, M. S. (2000). Health-related quality of life and virologic outcomes in an HIV clinic. In Quality of life research : an international journal of quality of life aspects of treatment, care and rehabilitation, 9(9), 977-985.

Cihlar, T., \& Fordyce, M. (2016). Current status and prospects of HIV treatment. In Current opinion in virology, 18, 50-56. https://doi.org/10.1016/j.coviro.2016.03.004.

Degroote, S., Vogelaers, D., \& Vandijck, D. M. (2014). What determines health-related quality of life among people living with HIV: an updated review of the literature. Archives of public health $=$ Archives belges de sante publique, 72(1), 40. https://doi.org/10.1186/2049-3258-72-40.

Deutsche AIDS-Gesellschaft (2012): Deutsche AIDS Gesellschaft und Österreichische AIDS Gesellschaft Deutsch-Österreichische Leitlinien zur antiretroviralen Therapie der HIV-Infektion. Stand März 2012, AWMF-Register-Nr. 055/0001. Available online at http://www.daignet.de/site-content/hiv-therapie/ leitlinien-1/Deutsch-Osterreichilsche\%20Leitlinien\%20zur\%20antiretroviralen\%20Therapie\%20der\% 20HIV-Infektion.pdf, checked on 2012.

Drewes, J., Ebert, J., Langer, P. C., Kleiber, D., \& Gusy, B. (2020). Social inequalities in health-related quality of life among people aging with HIV/AIDS: The role of comorbidities and disease severity. In Quality of life research : an international journal of quality of life aspects of treatment, care and rehabilitation., 29, 1549-1557. https://doi.org/10.1007/s11136-020-02413-9.

Esté, J. A., \& Cihlar, T. (2010). Current status and challenges of antiretroviral research and therapy. Antiviral Research, 85(1), 25-33. https://doi.org/10.1016/j.antiviral.2009.10.007.

Fleming, C. A., Christiansen, D., Nunes, D., Heeren, T., Thornton, D., Horsburgh, C. R., et al. (2004). Healthrelated quality of life of patients with HIV disease: Impact of hepatitis C coinfection. Clinical Infectious Diseases : An Official Publication of the Infectious Diseases Society of America, 38(4), 572-578. https:// doi.org/10.1086/381263.

Gibson, K., Rueda, S., Rourke, S. B., Bekele, T., Gardner, S., Fenta, H., \& Hart, T. A. (2011). Mastery and coping moderate the negative effect of acute and chronic stressors on mental health-related quality of life in HIV. AIDS Patient Care and STDs, 25(6), 371-381. https://doi.org/10.1089/apc.2010.0165.

Gueler, A., Moser, A., Calmy, A., Günthard, H. F., Bernasconi, E., Furrer, H., Fux, C. A., Battegay, M., Cavassini, M., Vernazza, P., Zwahlen, M., Egger, M., \& Swiss HIV Cohort Study, Swiss National Cohort. (2017). Life expectancy in HIV-positive persons in Switzerland: Matched comparison with general population. In AIDS (London, England), 31(3), 427-436. https://doi.org/10.1097/QAD. 0000000000001335.

Hays, R. D., Cunningham, W. E., Sherbourne, C. D., Wilson, I. B., Wu, A. W., Cleary, P. D., McCaffrey, D. F., Fleishman, J. A., Crystal, S., Collins, R., Eggan, F., Shapiro, M. F., \& Bozzette, S. A. (2000). Healthrelated quality of life in patients with human immunodeficiency virus infection in the United States: Results from the HIV cost and services utilization study. The American Journal of Medicine, 108(9), 714 722. https://doi.org/10.1016/s0002-9343(00)00387-9.

Heneine, W., \& Kashuba, A. (2012). HIV prevention by oral preexposure prophylaxis. In Cold Spring Harbor perspectives in medicine, 2(3), a007419. https://doi.org/10.1101/cshperspect.a007419.

Holzemer, W. L., Human, S., Arudo, J., Rosa, M. E., Hamilton, M. J., Corless, I., Robinson, L., Nicholas, P. K., Wantland, D. J., Moezzi, S., Willard, S., Kirksey, K., Portillo, C., Sefcik, E., Rivero-Méndez, M., \& Maryland, M. (2009). Exploring HIV stigma and quality of life for persons living with HIV infection. The Journal of the Association of Nurses in AIDS Care : JANAC, 20(3), 161-168. https://doi.org/10.1016/j. jana.2009.02.002. 
Horsman, J., Furlong, W., Feeny, D., \& Torrance, G. (2003). The health utilities index (HUI): Concepts, measurement properties and applications. In Health and quality of life outcomes, 1, 54. https://doi.org/10. 1186/1477-7525-1-54.

Jia, H., Uphold, C. R., Zheng, Y., Wu, S., Chen, G. J., Findley, K., \& Duncan, P. W. (2007). A further investigation of health-related quality of life over time among men with HIV infection in the HAART era. In Quality of life research : an international journal of quality of life aspects of treatment, care and rehabilitation, 16(6), 961-968. https://doi.org/10.1007/s11136-007-9214-4.

Kanwal, F., Gralnek, I. M., Hays, R. D., Dulai, G. S., Spiegel, B. M. R., Bozzette, S., \& Asch, S. (2005). Impact of chronic viral hepatitis on health-related quality of life in HIV: Results from a nationally representative sample. The American Journal of Gastroenterology, 100(9), 1984-1994. https://doi.org/10. 1111/j.1572-0241.2005.41962.x.

Kind, P. (1996). The EuroQol instrument: An index of health-related quality of life. In uality of Life and Pharmacoeconomics in Clinical Trials, 2, 191-201.

Korthuis, P. T., Zephyrin, L. C., Fleishman, J. A., Saha, S., Josephs, J. S., McGrath, M. M., et al. (2008). Health-related quality of life in HIV-infected patients: The role of substance use. AIDS Patient Care and STDs, 22(11), 859-867. https://doi.org/10.1089/apc.2008.0005.

Kuhlmann, A., Mittendorf, T., Hower, M., Heiken, H., Gerschmann, S., Klauke, S., Lutz, T., Bogner, J., Degen, O., van Lunzen, J., Bachmann, C., Stellbrink, H., Schmidt, W., Leistner, I., Mahlich, J., Ranneberg, B., \& Stoll, M. (2015). Krankheitskosten von HIV-Patienten unter antiretroviraler Therapie in Deutschland - Ergebnisse einer 48-Wochen-Interimsanalyse im Rahmen der prospektiven multizentrischen Kohortenstudie "CORSAR". Gesundheitswesen (Bundesverband der Arzte des Offentlichen Gesundheitsdienstes (Germany)), 77(6), e133-e142. https://doi.org/10.1055/s-00341381993.

Liu, C., Johnson, L., Ostrow, D., Silvestre, A., Visscher, B., \& Jacobson, L. P. (2006a). Predictors for lower quality of life in the HAART era among HIV-infected men. In Journal of acquired immune deficiency syndromes (1999), 42(4), 470-477. https://doi.org/10.1097/01.qai.0000225730.79610.61.

Liu, C., Ostrow, D., Detels, R., Hu, Z., Johnson, L., Kingsley, L., \& Jacobson, L. P. (2006b). Impacts of HIV infection and HAART use on quality of life. In Quality of life research : an international journal of quality of life aspects of treatment, care and rehabilitation, 15(6), 941-949. https://doi.org/10.1007/ s11136-005-5913-x.

Lundgren, J. D., Babiker, A. G., Gordin, F., Emery, S., Grund, B., Sharma, S., et al. (2015). Initiation of antiretroviral therapy in early asymptomatic HIV infection. The New England Journal of Medicine, 373(9), 795-807. https://doi.org/10.1056/NEJMoa1506816.

Mahlich, J., Bogner, J. R., Tomeczkowski, J., \& Stoll, M. (2015). Treatment strategies for treatment naïve HIV patients in Germany: Evidence from claims data. In SpringerPlus, 4, 306. https://doi.org/10.1186/s40064015-1099-z.

Mahlich, J., Groß, M., Kuhlmann, A., Bogner, J., Heiken, H., \& Stoll, M. (2016). The choice between a ritonavir-boosted protease inhibitor- and a non-nucleoside reverse transcriptase inhibitor-based regimen for initiation of antiretroviral treatment - results from an observational study in Germany. In Journal of pharmaceutical policy and practice, 9, 39. https://doi.org/10.1186/s40545-016-0092-4.

Mielck, A., Vogelmann, M., Schweikert, B., \& Leidl, R. (2010). Gesundheitszustand bei Erwachsenen in Deutschland: Ergebnisse einer repräsentativen Befragung mit dem EuroQol 5D (EQ-5D). Gesundheitswesen (Bundesverband der Arzte des Offentlichen Gesundheitsdienstes (Germany)), 72(89), 476-486. https://doi.org/10.1055/s-0029-1239508.

Murri, R., Ammassari, A., Fantoni, M., Scoppettuolo, G., Cingolani, A., de Luca, A., Damiano, F., \& Antinori, A. (1997). Disease-related factors associated with health-related quality of life in people with nonadvanced HIV disease assessed using an Italian version of the MOS-HIV health survey. Journal of acquired immune deficiency syndromes and human retrovirology : official publication of the International Retrovirology Association, 16(5), 350-356.

NICE (2014): Developing NICE guidelines: The manual. Process and methods. Available online at https:// www.nice.org.uk/process/pmg20/chapter/introduction-and-overview, updated on 2018, checked on 8/23/ 2019.

Pharmaceutical Benefits Advisory Committee (2016): Guidelines for preparing submissions to the Pharmaceutical Benefits Advisory Committee. Available online at https://pbac.pbs.gov.au/, checked on $8 / 23 / 2019$.

Pichenot, M., Deuffic-Burban, S., Cuzin, L., \& Yazdanpanah, Y. (2012). Efficacy of new antiretroviral drugs in treatment-experienced HIV-infected patients: A systematic review and meta-analysis of recent randomized controlled trials. HIV Medicine, 13(3), 148-155. https://doi.org/10.1111/j.1468-1293.2011. 00953.x. 
Préau, M., Marcellin, F., Carrieri, M. P., Lert, F., Obadia, Y., \& Spire, B. (2007a). Health-related quality of life in French people living with HIV in 2003: results from the national ANRS-EN12-VESPA Study. AIDS (London, England), 21(1), S19-S27. https://doi.org/10.1097/01.aids.0000255081.24105.d7.

Préau, M., Protopopescu, C., Spire, B., Sobel, A., Dellamonica, P., Moatti, J.-P., \& Carrieri, M. P. (2007b). Health related quality of life among both current and former injection drug users who are HIV-infected. Drug and Alcohol Dependence, 86(2-3), 175-182. https://doi.org/10.1016/j.drugalcdep.2006.06.012.

Protopopescu, C., Marcellin, F., Spire, B., Préau, M., Verdon, R., Peyramond, D., Raffi, F., Chêne, G., Leport, C., \& Carrieri, M.-P. (2007). Health-related quality of life in HIV-1-infected patients on HAART: A fiveyears longitudinal analysis accounting for dropout in the APROCO-COPILOTE cohort (ANRS CO-8). In Quality of life research : an international journal of quality of life aspects of treatment, care and rehabilitation, 16(4), 577-591. https://doi.org/10.1007/s11136-006-9151-7.

Rao, D., Hahn, E. A., Cella, D., \& Hernandez, L. (2007). The health related quality of life outcomes of English and Spanish speaking persons living with HIV/AIDS from the continental United States and Puerto Rico. AIDS Patient Care and STDs, 21(5), 339-346. https://doi.org/10.1089/apc.2006.0124.

Robert Koch-Institut (2018): Schätzung der Zahl der HIV-Neuinfektionen und der Gesamtzahl von Menschen mit HIV in Deutschland. Stand Ende 2017. [Estimation of the number of new HIV infections and the total number of people with HIV in Germany as of the end of 2017]. In Epidemiologisches Bulletin (47), pp. 509-522. Available online at https://www.rki.de/DE/Content/Infekt/EpidBull/Archiv/2018/Ausgab, checked on $9 / 2 / 2019$.

Ruiz Perez, I., Rodriguez Baño, J., Lopez Ruz, M. A., del Arco Jimenez, A., Causse Prados, M., Pasquau Liaño, J., et al. (2005). Health-related quality of life of patients with HIV: Impact of socio-demographic, clinical and psychosocial factors. In Quality of life research : an international journal of quality of life aspects of treatment, care and rehabilitation, 14(5), 1301-1310.

Sabranski, Michael, Erdbeer, Gesa, Sonntag, Ina, Stoehr, Albrecht, Horst, Heinz-August, Plettenberg, Andreas et al. (2020): Physical and mental health in HIV-infected patients with virological success and long-term exposure to antiretroviral therapy. In AIDS care, pp. 1-9. https://doi.org/10.1080/09540121.2020. 1733466.

Sanders, G. D., Neumann, P. J., Basu, A., Brock, D. W., Feeny, D., Krahn, M., Kuntz, K. M., Meltzer, D. O., Owens, D. K., Prosser, L. A., Salomon, J. A., Sculpher, M. J., Trikalinos, T. A., Russell, L. B., Siegel, J. E., \& Ganiats, T. G. (2016). Recommendations for conduct, methodological practices, and reporting of cost-effectiveness analyses: Second panel on cost-effectiveness in health and medicine. JAMA, 316(10), 1093-1103. https://doi.org/10.1001/jama.2016.12195.

Schroecksnadel, K., Sarcletti, M., Winkler, C., Mumelter, B., Weiss, G., Fuchs, D., Kemmler, G., \& Zangerle, R. (2008). Quality of life and immune activation in patients with HIV-infection. In Brain, behavior, and immunity, 22(6), 881-889. https://doi.org/10.1016/j.bbi.2007.12.011.

Stasinopoulos, M, D. (2017): Flexible regression and smoothing. Using GAMLSS in R. Boca Raton: CRC Press/Taylor \& Francis Group (Chapman \& Hall/CRC the R series).

Stoll, M., \& Schmidt, R. E. (2004). Immune restoration inflammatory syndromes: Apparently paradoxical clinical events after the initiation of HAART. Current HIV/AIDS Reports, 1(3), 122-127.

Teeraananchai, S., Kerr, S. J., Amin, J., Ruxrungtham, K., \& Law, M. G. (2017). Life expectancy of HIVpositive people after starting combination antiretroviral therapy: A meta-analysis. HIV Medicine, 18(4), 256-266. https://doi.org/10.1111/hiv.12421.

Treskova, M., Kuhlmann, A., Bogner, J., Hower, M., Heiken, H., Stellbrink, H.-J., Mahlich, J., Schulenburg, J.-M. G. v. d., \& Stoll, M. (2016). Analysis of contemporary HIV/AIDS health care costs in Germany: Driving factors and distribution across antiretroviral therapy lines. In Medicine, 95(26), e3961. https://doi. org/10.1097/MD.0000000000003961.

Venturini, A., Giannini, B., Montefiori, M., Di Biagio, A., Mazzarello, G., Cenderello, G., et al. (2014). Quality of life of people living with HIV, preliminary results from IANUA (Investigation on Antiretroviral Therapy) study. Journal of the International AIDS Society, 17(4 Suppl 3), 19581. https:// doi.org/10.7448/IAS.17.4.19581.

Whitehead, S. J., \& Ali, S. (2010). Health outcomes in economic evaluation: The QALY and utilities. In British medical bulletin, 96, 5-21. https://doi.org/10.1093/bmb/ldq033.

World Health Organization (2002): WHOQOL-HIV Instrument. Available online at http://www.who.int/ mental health/media/en/557.pdf, checked on 8/25/2019.

Zinkernagel, C., Ledergerber, B., Battegay, M., Cone, R. W., Vernazza, P., Hirschel, B., \& Opravil, M. (1999). Quality of life in asymptomatic patients with early HIV infection initiating antiretroviral therapy. Swiss HIV cohort study. In AIDS (London, England), 13(12), 1587-1589. https://doi.org/10.1097/ 00002030-199908200-00024. 
Zinkernagel, C., Taffé, P., Rickenbach, M., Amiet, R., Ledergerber, B., Volkart, A. C., Rauchfleisch, U., Kiss, A., Werder, V., Vernazza, P., Battegay, M., \& Swiss HIV Cohort Study. (2001). Importance of mental health assessment in HIV-infected outpatients. In Journal of acquired immune deficiency syndromes (1999), 28(3), 240-249.

Zorginstituut Nederland (2016): Guideline for economic evaluations in healthcare. Available online at https:// tools.ispor.org/PEguidelines/source/Netherlands_Guideline_for_economic_evaluations_in_healthcare. pdf, checked on $8 / 23 / 2019$.

Publisher's Note Springer Nature remains neutral with regard to jurisdictional claims in published maps and institutional affiliations.

\section{Affiliations}

\section{Martina Treskova ${ }^{1} \cdot$ Stefan Scholz ${ }^{1} \cdot$ Alexander Kuhlmann $^{1} \cdot$ Jörg Mahlich $^{2,3}$ • Matthias Stoll ${ }^{4}$}

Stefan Scholz

sts@cherh.de

Alexander Kuhlmann

ak@cherh.de

Jörg Mahlich

joerg.mahlich@gmail.com; mahlich@dice.hhu.de

Matthias Stoll

stoll.matthias@mh-hannover.de

1 Centre for Health Economics Research, University of Hannover, Otto-Brenner-Str.1, 30159 Hannover, Germany

2 Health Economics, Janssen KK, Tokyo, Japan

3 Heinrich-Heine University of Düsseldorf, Düsseldorf Institute for Competition Economics (DICE), Düsseldorf, Germany

4 Clinic for Immunology and Rheumatology, Hannover Medical School (MHH), Hanover, Germany 